\title{
Identifikasi Keunikan Lansekap Kampung Loloan di Jembrana
}

\author{
NI WAYAN FEBRIANA UTAMI ${ }^{\star}$, NANIEK KOHDRATA ${ }^{1}$ \\ 1. Program Studi Arsitektur Pertamanan, Fakultas Pertanian, Universitas Udayana \\ Gedung Agrokompleks Lt. 2 Wing Barat, Jl. PB Sudirman Denpasar 80232, Indonesia
}

*E-mail: wayan_febriana@unud.ac.id

\begin{abstract}
Identification on Distinctive Landscape of Kampong Loloan in Jembrana

Most of landscape in Bali is closely related to Hindu's culture. In contrary, it is different in Kampong Loloan which is an area located in the ljogading riverbank in Negara District, Jembrana Regency, Bali Province. It is unique because of the people and the culture, more and less, are identically similar to Malay culture. Their ancestors are mostly Malay or Bugis people or other ethnicities. The objective of this study was to identify the biophysical and social characteristic of Kampong Loloan along with spatial distribution of cultural and historical site found on the area. The methods used was conducted with three phase, 1) data collection with ground thruth check and literature study; 2) data analysis of biophysical and social character with spatial analysis; and 3) synthesis of cultural characteristics. The results showed that land use patterns in Kampong Loloan was based on river ecological zone. Three zone were identify, 1) the upstream zone (Ketugtug and Pertukangan sub-village); 2) the midstream zone (Loloan Timur and Kerobokan subvillage), and 3) the downstream zone (Mertasari and Terusan sub-village). The tangible heritage found in Loloan was stilt houses (rumah panggung) but the existence was threatened. Moreover, Malay-Loloan language, Adrah musical art, and Bugis martial art were found as the intangible heritage. Map analysis showed that cultural and historical site in Kampong Loloan were mostly found in the east side of ljogading riverbank.
\end{abstract}

Keywords: cultural landscape, ljogading riverbank, Loloan, vernacular landscape,

\section{Pendahuluan}

Kampung Loloan terletak di Kabupaten Jembrana, Provinsi Bali merupakan sebuah kampung yang terbentuk dari dua wilayah kelurahan yaitu Kelurahan Loloan Timur dan Loloan Barat. Kedua wilayah ini dipisahkan oleh sebuah sungai bernama Sungai ljogading. Masyarakat yang mendiami Kampung Loloan didominasi oleh etnis Melayu (Pahang, Johor, Kedah, Trengganu), Bugis (Sulawesi Selatan), Arab, Cina, dan Jawa, selain etnis lokal Bali (Suryawati, 2010). Keberadaan etnis pendatang di Loloan tidak terlepas dari sejarah masuknya Islam di Kerajaan Jembrana pada abad 17 dan 18 dimana keberadaannya turut mewarnai sejarah Kerajaan Jembrana dalam mempertahankan wilayah Jembrana dari pendudukan penjajahan pada masa itu.

Dengan adanya nilai keunikan yang dimiliki Kampung Loloan terkait sejarah dan budaya, serta nilai fisik alami yang terkandung di dalamnya menjadi dasar pentingnya kajian lansekap budaya di Kampung Loloan dengan tujuan pelestarian. Sehingga dengan semakin intensifnya perubahan dan keragaman bentuk yang dijumpai pada lansekap Kampung Loloan saat ini perlu dilakukan kajian identifikasi terhadap karakter lansekap yang ada dengan memperhatikan bentukan lansekap tradisional di Kampung Loloan. Hal ini penting dilakukan dalam rangka mencegah penurunan nilai sejarah dan budaya di Kampung Loloan sekaligus memberikan pedoman atau rekomendasi bagi pemerintah, 
masyarakat, dan pihak terkait lainnya dalam menentukan arah perencanaan atau pengembangan Kampung Loloan yang berkelanjutan.

\section{Metode}

\subsection{Waktu dan Lokasi Penelitian}

Penelitian ini dilakukan pada bulan Mei sampai November 2015 di Kelurahan Loloan Timur dan Kelurahan Loloan Barat, Kabupaten Jembrana, Provinsi Bali (Gambar 1). Penelitian ini meliputi tahap inventarisasi, analisis, dan sintesis (Gambar 2).

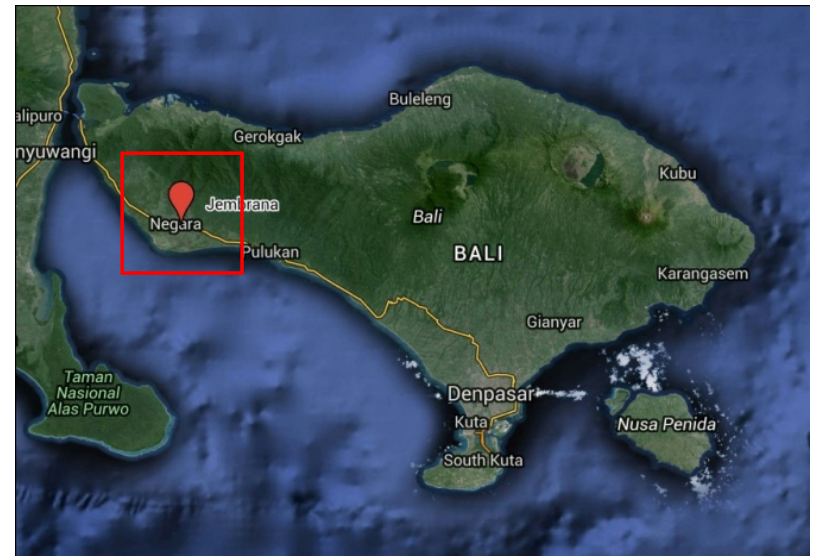

Gambar 1. Peta Orientasi Lokasi Penelitian

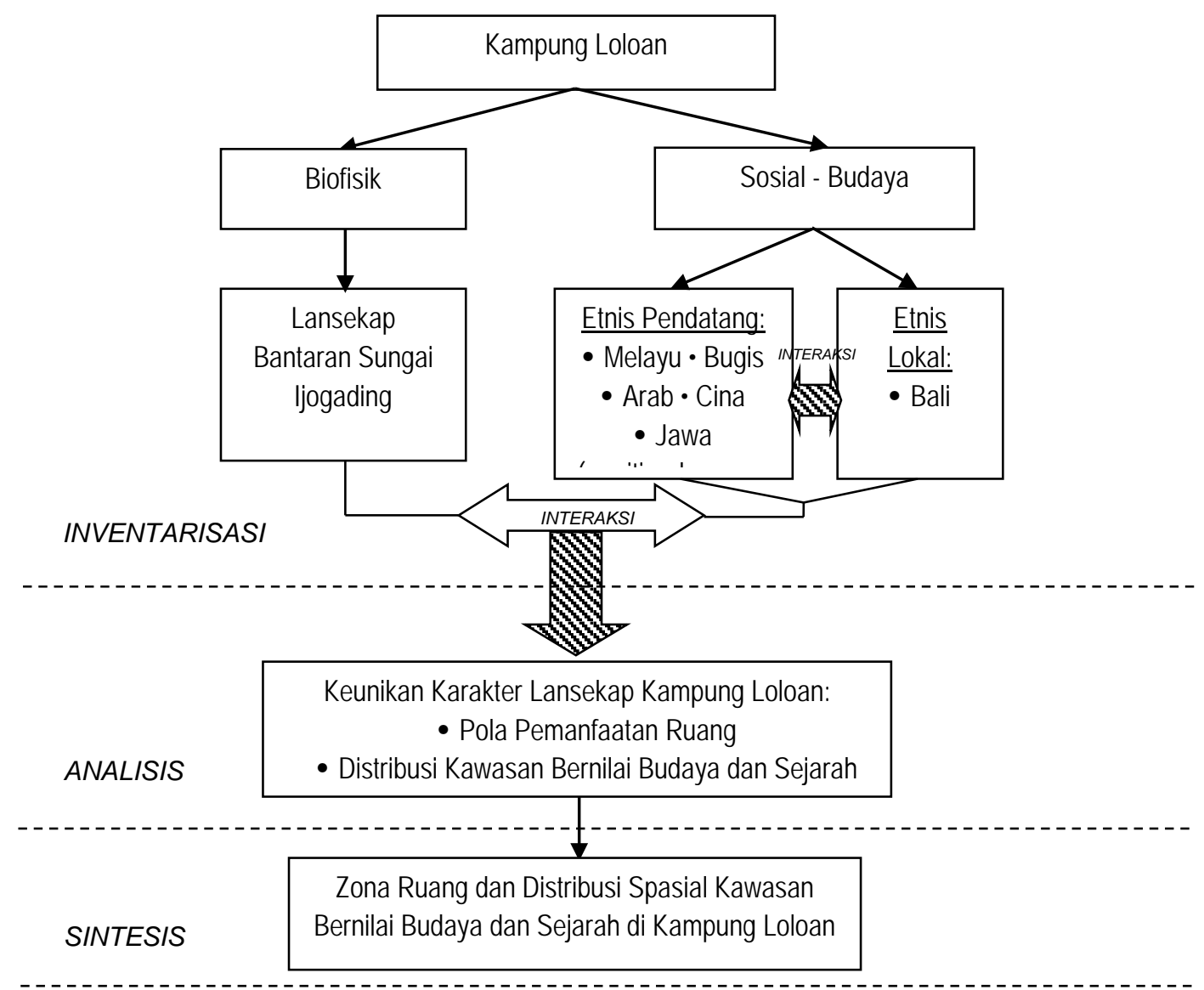

Gambar 2. Bagan Alir Penelitian 


\subsection{Metode Pengumpulan Data}

\subsubsection{Inventarisasi Data Biofisik}

Pengamatan dilakukan secara langsung maupun tidak langsung untuk mendapatkan informasi mengenai kondisi biofisik pada lokasi penelitian antara lain data terkait wilayah administrasi, profil kelurahan, iklim dan kondisi geologi serta topografi, hidrologi, tutupan lahan, serta ground truth check kawasan bernilai budaya dan sejarah

\subsubsection{Inventarisasi Data Sosial-Budaya}

Pengamatan dilakukan secara langsung maupun tidak langsung untuk mendapatkan informasi mengenai kondisi demografi masyarakat yang ada di Kelurahan Loloan Timur dan Loloan Barat, lembaga kemasyarakatan, sistem adat dan budaya, sejarah, filosofi dan nilai-nilai spiritual budaya.

\subsection{Metode Analisis Data}

\subsubsection{Analisis Deskriptif}

Analisis deskriptif dilakukan untuk menjelaskan kekhasan biofisik dan budaya di Kampung Loloan antara lain deskripsi mangenai kondisi penduduk, lembaga sosial kemasyarakatan dan sistem adat dan budaya.

\subsubsection{Analisis Spasial}

Analisis spasial dilakukan untuk memetakan pengorganisasian ruang di Kampung Loloan sebagai bentuk interaksi masyarakat dengan lingkungan fisiknya. Termasuk juga distribusi kawasan bernilai sejarah dan budaya dimana penentuan kriterianya memenuhi unsur benda (tangible) maupun tak benda (intangible).

\subsubsection{Analisis Penelusuran Sejarah}

Analisis ini dilakukan dengan menelusuri sejarah terbentuknya Kampung Loloan terkait dengan masuknya etnis pendatang ke Jembrana hingga akhirnya menetap di Kampung Loloan sekarang ini.

\subsection{Sintesis}

Hasil penelitian ini menghasilkan Peta Zona Ruang Kawasan dan Distribusi Kawasan Bernilai Budaya dan Sejarah di Kampung Loloan dan juga deskripsi mengenai keunikan karakter yang menjadi ciri lansekap di Kampung Loloan.

\section{Hasil dan Pembahasan}

\subsection{Keunikan Karakter Lansekap Kampung Loloan}

\subsubsection{Karakteristik Biofisik}

Kampung Loloan terbentuk dari dua wilayah administrasi yaitu Kelurahan Loloan Timur yang terletak di Kecamatan Jembrana dan Kelurahan Loloan Barat yang terletak di Kecamatan Negara, Kabupaten Jembrana, Provinsi Bali. Keduanya dipisahkan oleh Sungai ljogading yang membentang sepanjang 19.200 meter dari hulu ke hilir (Gambar 3). Masing-masing wilayah kelurahan tersebut memiliki tiga sub-wilayah kelurahan yang disebut dengan "lingkungan" atau setara banjar untuk wilayah Bali atau RW di wilayah lain. Kelurahan Loloan Timur terdiri dari sub-wilayah Lingkungan Ketugtug, Lingkungan Loloan Timur, dan Lingkungan Mertasari. Sedangkan Kelurahan Loloan Barat terdiri dari subwilayah Lingkungan Pertukangan, Lingkungan Kerobokan, dan Lingkungan Terusan. Total luas kedua wilayah kelurahan ini adalah 5,81 $\mathrm{Km}^{2}$. 


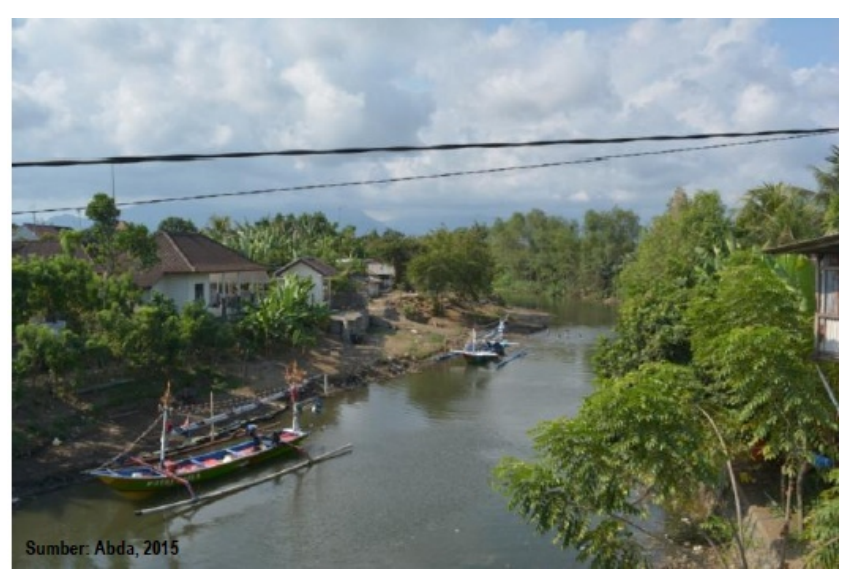

Gambar 3. Lansekap Kampung Loloan Dilihat dari atas Jembatan Syarif Tua

Karakter biofisik di kedua wilayah relatif sama dengan bentukan topografi datar (0,35,3 derajat) dan memiliki tipe iklim $C$ sampai $D$ (Schmidt dan Ferguson). Namun, terdapat aspek yang membedakan keduanya yaitu kondisi hidrologi dimana sumber air yang dijumpai di Kelurahan Loloan Timur selain berasal dari sungai ljogading juga terdapat sistem pengairan jelinjing Loloan atau sejenis sungai kecil yang berfungsi sebagai irigasi sawah. Berbedaan sistem hidrologi ini tentu saja tidak terlepas dari kondisi tutupan lahan di daearh tersebut yang membentuk keragaman patch yang terdiri dari patch yang berupa lahan pertanian seperti kebun $(28,05 \%)$, tegal $(25,20 \%)$, dan sawah $(23,80 \%)$ serta patch pekarangan (21,56\%) dan penggunaan lainnya (mencapai 1,39\%). Sedangkan wilayah Loloan Barat keragaman patch-nya lebih sedikit yaitu berupa patch pekarangan $(46,26 \%)$ dan sisanya adalah merupakan patch jenis penggunaan lainnya (53,74\%) (Gambar 4).

Keterangan:

口: Batas Kelurahan Loloan Barat

口: Batas Kelurahan Loloan Timur

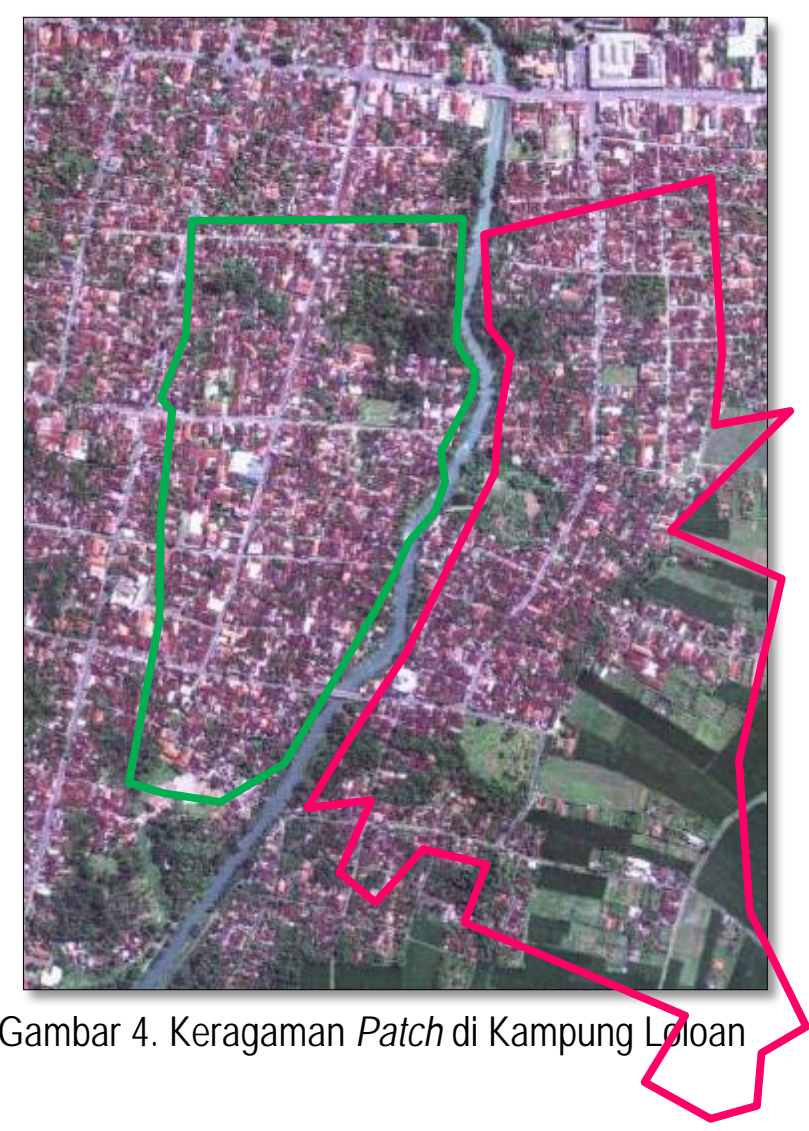

http://ojs.unud.ac.id/index.php/lanskap 
Dengan adanya keragaman patch yang tinggi di wilayah Loloan Timur yang merupakan bagian dari keragaman lansekap secara keseluruhan dari wilayah Kampung Loloan. Keragaman patch memiliki korelasi salah satunya terhadap konservasi keragaman hayati yaitu dengan memperhatikan interkoneksi diantara patch (Bojie, 1996) sehingga keragaman hayati di Kampung Loloan khususnya Kelurahan Loloan Timur tetap terjaga.

\subsubsection{Karakteristik Sosial}

Secara formal, kepemimpinan tertinggi di wilayah Kelurahan Loloan Timur dan Loloan Barat dipimpin seorang lurah dibantu oleh kaling (kepala wilayah) sebagai pimpinan sub-wilayah. Sebaliknya, secara informal kepemimpinan di Kampung Loloan didasari oleh pengakuan dan kepercayaan masyarakat terhadap tokoh yang berasal dari golongan berpangkat, ulama, maupun pemuka agama (Suryawati, 2009). Hal ini bisa dilihat dari peran signifikan dari beberapa alim ulama yang berada di kedua wilayah. Selain itu juga terdapat bentuk kepemimpinan lembaga adat desa pakraman Mertasari yang dijumpai di Kelurahan Loloan Timur.

Dilihat dari komposisi masyarakatnya, etnis terbanyak yang bermukim di Loloan Timur dan Loloan Barat berturut-turut adalah etnis Melayu dan Bugis. Hal ini memiliki korelasi positif dengan mata pencaharian pokok masyarakat di wilayah tersebut dimana terdapat sebanyak 540 jiwa penduduk di Kelurahan Loloan Barat bermata pencaharian sebagai nelayan (Profil Kelurahan Loloan Barat, 2014). Selain itu, bentuk hubungan masyarakat dengan lingkungan tempat tinggalnya sangat harmonis dengan kehidupan mayarakat Bugis pada umumnya dengan model dan bentuk tempat tinggal berupa arsitektur tradisional rumah panggung (Gambar 5). Rumah panggung menjadi ciri karakter permukiman di Kampung Loloan.

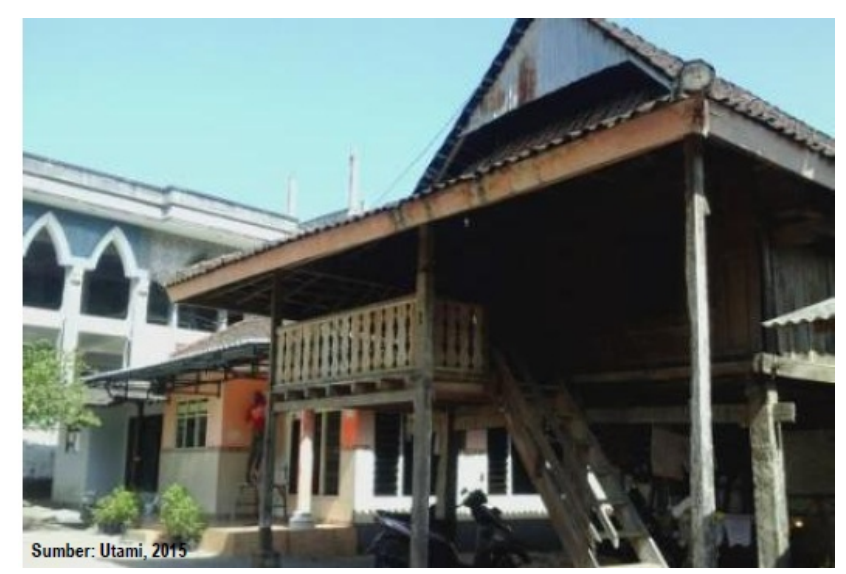

Gambar 5. Rumah Panggung Khas Masyarakat Kampung Loloan, Jembrana

Etnis Bugis sebagai salah satu kelompok masyarakat pertama yang datang dan menetap di Kampung Loloan merupakan mayarakat bahari yang dikenal memiliki model tempat tinggal berpanggung. Bentuk rumah panggung ini dipilih bukan saja karena merupakan kekhasan budaya Bugis maupun Melayu, namun juga merupakan bentuk adaptasi masyarakat Loloan terhadap lingkungan fisiknya, terutama bentuk adaptasi terhadap bencana banjir (Pramesti, 2013). Dalam penelitian yang sama, Pramesti menunjukkan bahwa terdapat pengurangan jumlah rumah panggung dan saat ini tersisa sekitar 85 rumah panggung. Ancaman kepunahan rumah panggung secara umum diakibatkan oleh kondisi ekonomi dimana biaya pembuatan maupun pemeliharaan rumah panggung dirasa masyarakat lebih mahal dibandingkan dengan rumah bergaya modern. 
Selain unsur kebendaan (tangible), terdapat pula hal menarik lainnya yang membentuk karakter sosial kemasyarakatan di Kampung Loloan yaitu bahwa dengan adanya dominansi etnis pendatang tidak serta merta menyebabkan budaya Bali menjadi luntur. Diantara etnis pendatang dengan etnis lokal Bali terjadi kontak sosial dimana terjadinya kontak sosial tersebut salah satunya dengan komunikasi melalui media bahasa. Mayoritas penduduk pendatang menggunakan bahasa Melayu sedangkan masyarakat lokal Bali menggunakan bahasa Bali. Terdapat pengaruh bahasa Bali terhadap percakapan dengan bahasa Melayu Loloan yaitu dalam unsur bahasa, kosakata, bunyi dan bidang bahasa Bali lainnya. Hal ini sejalan dengan yang diungkapkan oleh Suparwa (2008) bahwa pengaruh bahasa Bali terdapat pada bahasa Melayu Loloan yaitu melalui proses penyerapan secara utuh maupun melalui perubahan bentuk.

\subsection{Pola Pemanfaatan Ruang dan Distribusi Spasial Kawasan Bernilai Budaya dan Sejarah di Kampung Loloan}

Asal kata Loloan menurut sejarah berasal dari bahasa Melayu yaitu Liloan yang berarti lekukan. Bentuk lekukan seperti yang dimaksud oleh generasi terdahulu tersebut telah mengalami perubahan dengan yang ada sekarang. Saat ini, kondisi sungai ljogading tidak lagi berkelok seperti dulu namun sudah mengalami pelurusan atau normalisasi oleh pemerintah sebagi upaya menanggulangi banjir yang sering terjadi di Kampung Loloan. Area bekas lekukan dari badan sungai yang mengalami pelurusan tersebut saat ini berubah fungsi menjadi daratan dan berupa tanah rawa. Masyarakat Kampung Loloan menyebutnya dengan istilah kebonan. Area kebonan saat ini difungsikan oleh masyarakat Kampung Loloan untuk berbagai fasilitas umum seperti kandang ternak, kolam ikan, lapangan olahraga, tempat menjemur, serta ada beberapa area tanah rawa tersebut yang ditimbun dan diratakan untuk selanjutnya dijadikan area permukiman (Gambar 6). Permukiman ini ditujukan terutama bagi masyarakat yang mengalami relokasi pelebaran jalan di Kelurahan Loloan Barat.
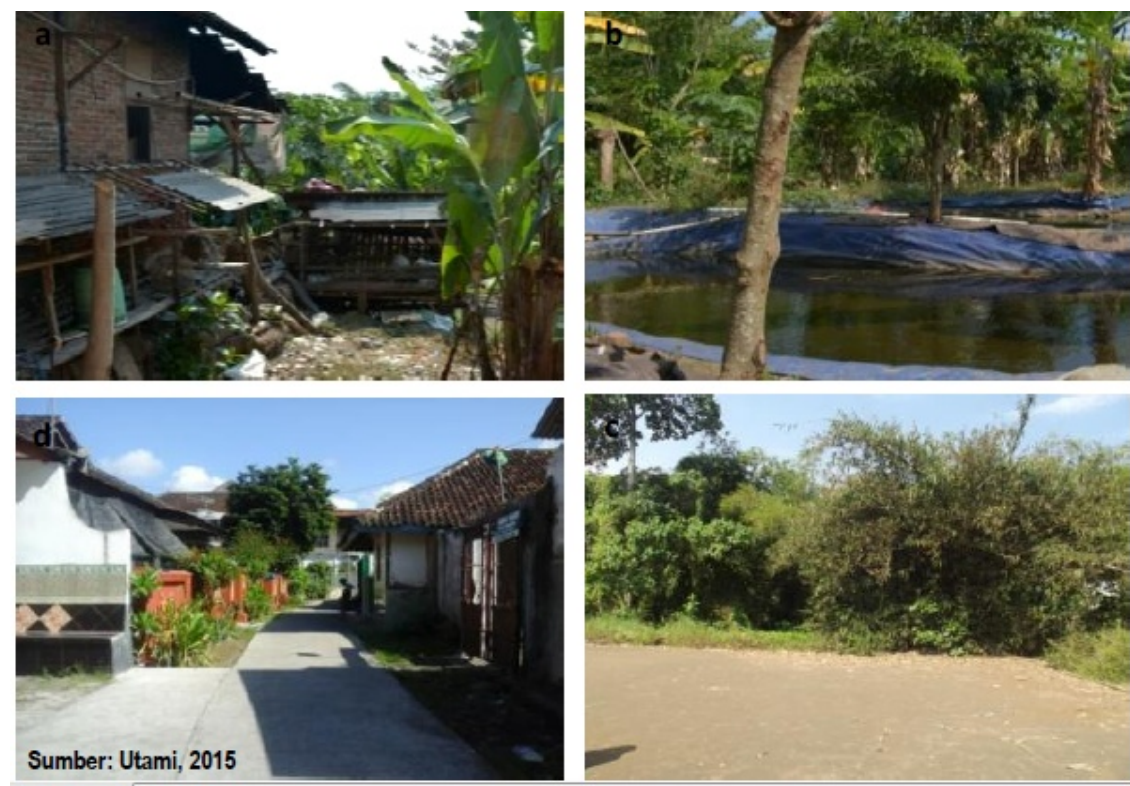

Gambar 6. Pemanfaatan Tanah Kebonan

(a. kandang ternak, b. kolam ikan, c. lapangan, d. permukiman)

Secara spasial, wilayah Kampung Loloan membentang dari utara sampai selatan disepanjang riparian sungai ljogading di tengah Kota Negara. Wilayah tersebut berturut- 
turut adalah Lingkungan Ketugtug dan Lingkungan Pertukangan di bagian utara, Lingkungan Loloan Timur dan Lingkungan Kerobokan di bagian tengah, dan Lingkungan Mertasari serta Lingkungan Terusan bagian selatan. Pembagian sub-wilayah tersebut berdasarkan pada pembagian wilayah ekologi sungai dan juga merupakan istilah yang digunakan masyarakat bahari yaitu masyarakat Bugis. Istilah itulah yang kemudian berkembang di Kampung Loloan dan dijadikan dasar pembagian zona wilayah kampung (Gambar 7). Orang hulu merujuk kepada masyarakat yang bertempat tinggal di wilayah paling utara, orang tengah merujuk pada masyarakat yang bermukim di tengah-tengah zona, dan orang hilir murujuk kepada masyarakat yang tinggal di bagian selatan dan lebih dekat dengan laut. Dengan digunakannya istilah orang hulu (zona hulu), orang tengah (zona tengah), dan orang hilir (zona hilir) membuktikan bahwa faktor alam maupun faktor sosial budaya merupakan dasar berkembangnya pembagian zona wilayah dan istilah dalam bahasa Bugis berpengaruh kuat terhadap penamaan wilayah di Kampung Loloan.

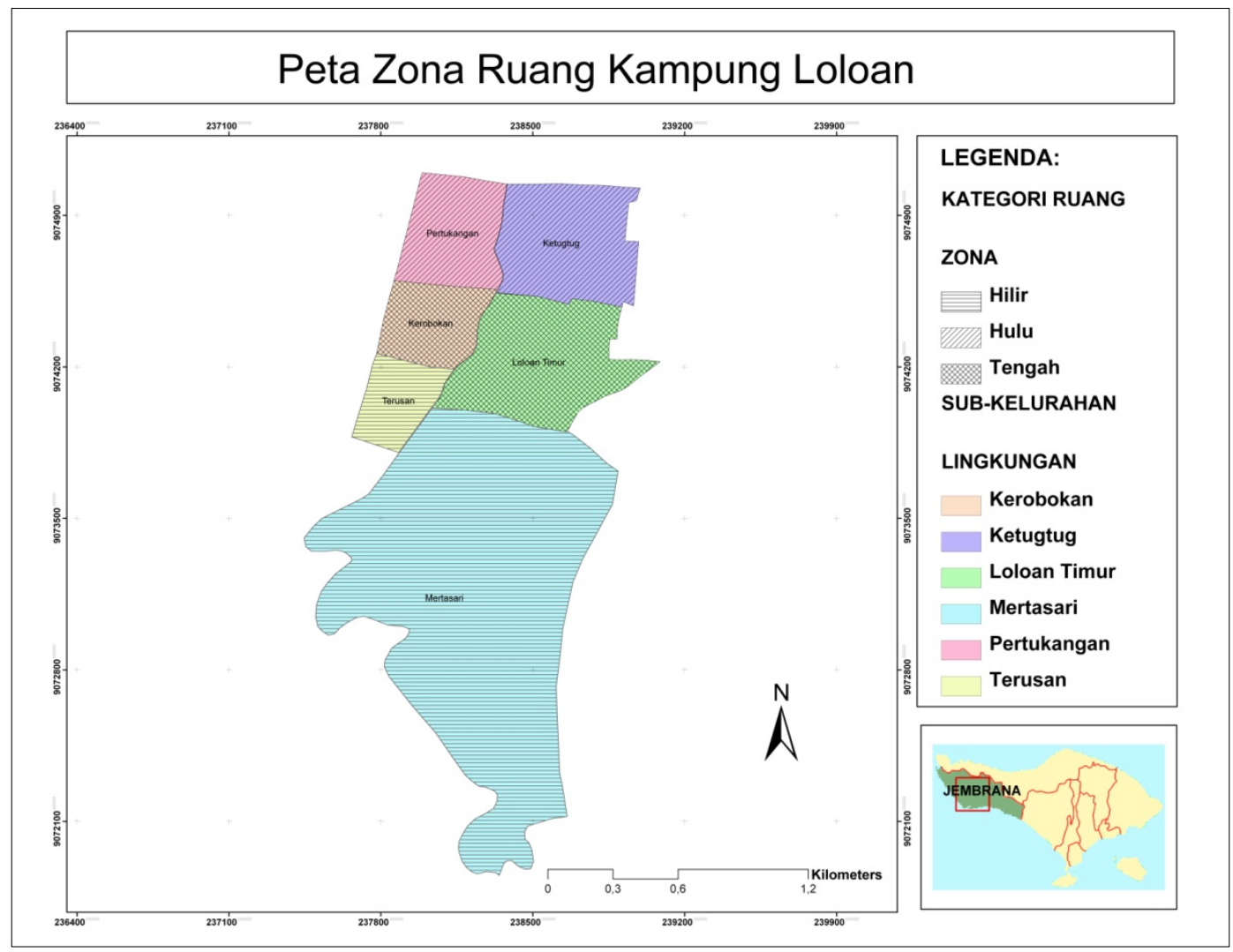

Gambar 7. Peta Zona Ruang di Kampung Loloan

Dilihat dari distribusi kawasan budaya dan sejarah, terdapat beberapa produk budaya dan sejarah yang dijumpai di Kampung Loloan yang dikelompokkan menjadi jenis produk budaya benda (tangible) dan jenis produk budaya tak benda (intangible). Produk budaya benda yang teridentifikasi antara lain: Jembatan Syarif Tua, Kompleks Makam Auliyaiyah di belakang Masjid Baitu Qadim, Masjid Baitul Qadim, Makam Buyut Lebai, Prasasti Loloan, Rumah Panggung, dan Sungai ljogading. Sedangkan produk budayan tak benda yang teridentifikasi antara lain: Bahasa Melayu Loloan, Kesenian Adrah (rebana), Sejarah Benteng Fatimah, dan Silat Bugis (Tabel 1). 
Tabel 1. Inventarisasi Produk Budaya dan Sejarah Kampung Loloan

\begin{tabular}{lll}
\hline \multicolumn{1}{c}{ Jenis } & \multicolumn{1}{c}{ Lokasi } & \\
\hline Benda (tangible) & & 4 \\
1. Jembatan Syarif Tua & Loloan Timur dan Loloan Barat & 4 \\
2. Kompleks Makam Auliyaillah & Loloan Timur & 4 \\
3. Makam Buyut Lebai & Loloan Timur & 4 \\
4. Masjid Baitul Qadim & Loloan Timur & 4 \\
5. Prasasti Loloan & Loloan Timur & 4 \\
6. Rumah Panggung & Loloan Timur dan Loloan Barat & 4 \\
7. Sungai ljogading & Loloan Timur dan Loloan Barat & \\
Tak Benda (intangible) & & 4 \\
1. Bahasa Melayu Loloan & Loloan Timur dan Loloan Barat & 4 \\
2. Kesenian Adrah & Loloan Timur dan Loloan Barat & 4 \\
3. Sejarah Benteng Fatimah & Loloan Timur dan Loloan Barat & 4 \\
4. Silat Bugis & Loloan Timur dan Loloan Barat & 3 \\
\hline
\end{tabular}

Sumber: Observasi, pustaka, dan kuesioner, 2015

Keterangan: $5=$ sangat bernilai budaya tinggi; 4=bernilai budaya tinggi; 3=kurang bernilai budaya; 2=tidak benilai budaya; 1=tidak tahu

Tabel tersebut menjelaskan bahwa terdapat satu jenis produk budaya yang mendapat skor 3 (kurang bernilai budaya) yaitu seni beladiri silat Bugis. Sedangkan sisanya mendapat skor 4 (bernilai budaya tinggi). Menurut hasil wawancara yang dilakukan dengan masyarakat sekitar, seni beladiri silat Bugis saat ini sudah tidak banyak lagi yang mempelajarinya. Hal ini disebabkan karena adanya keterbatasan pelatih yang menguasai seni beladiri ini. Selain itu permasalahan lainnya adalah pelaksanaan waktu pelatihan yang biasanya dilakukan pada malam hari dan dengan disertai ritual tertentu yang tidak bersesuaian dengan ajaran Islam, sehingga hal inilah yang menyebabkan kegiatan seni ini tidak lagi dipelajari khususnya oleh generasi muda yang ada dari Kampung Loloan.

Adapun distribusi produk budaya dan sejarah khususnya produk budaya benda lebih banyak ditemukan di Loloan Timur. Hal ini karena kelompok pendatang pegelombang rtama yang datang ke Jembrana berasal dari Sulawesi Selatan dan Kalimantan Barat kebanyakan bermukim di Loloan Timur. Sedangkan kelompok pendatang gelombang kedua yang kebanyakan berasal dari Jawa, Madura, dan Sasak lebih banyak bermukim di Loloan Barat (Suryawati, 2009). Sehingga dapat dikatakan bahwa produk-produk budaya yang banyak dijumpai saat ini sebagian besar merupakan warisan budaya etnis Melayu dan Bugis yang bertempat tinggal di Loloan Timur sehingga distribusi produk budaya tersebut lebih banyak dijumpai di Loloan Timur (Gambar 8).

Hasil analisis spasial distribusi warisan budaya benda maupun beberapa lokasi penting lainnya yan dijumpai di Kampung Loloan antara lain jembatan Syarif Tua (diambil dari nama Syarif Abdullah bin Yahya Maulana Al Qadry), sungai ljogading, Masjid Baitul Qadim (termasuk prasasti Loloan dan makam Auliyaiyah di belakang masjid, rumah panggung, lokasi bekas situs benteng Fatimah, makam Buyut Lebai, maupun tanah kebonan yang terletak di sisi timur sungai (Gambar 9). 
1. Komplek Makam Auliyaillah

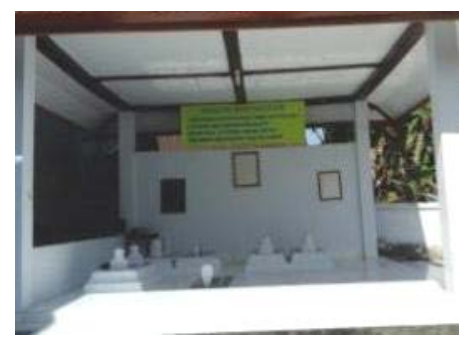

2. Rumah Panggung Melayu

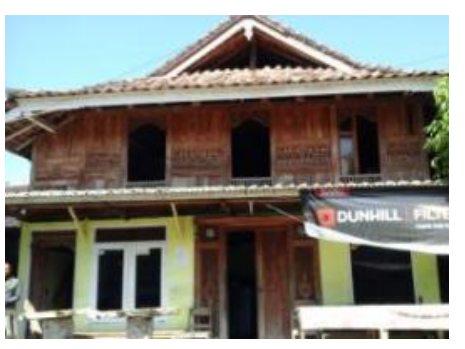

3. Makam Buyut Lebai

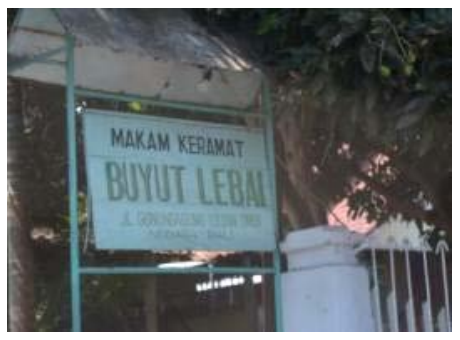

3

2

2
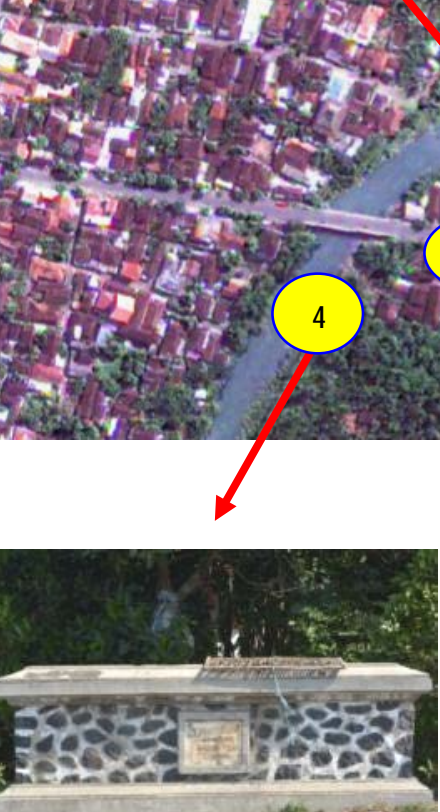

Sumber: Utami, 2015

4. Jembatan Syarif Tua

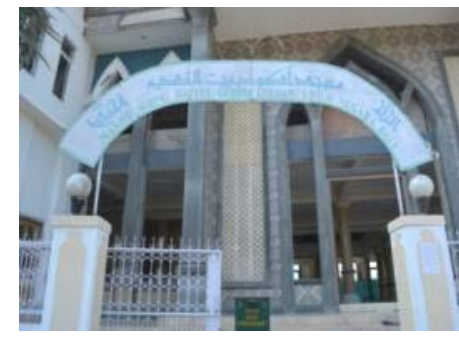

5a. Masjid Baitul Qadim

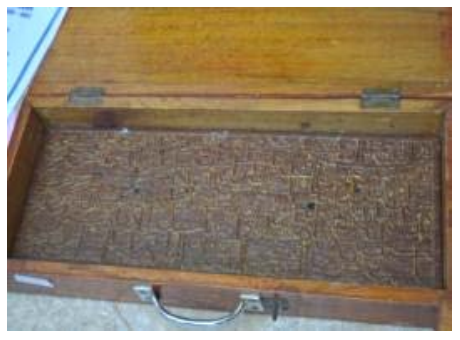

5b. Prasasti Loloan

Gambar 8. Produk Budaya Benda di Kampung Loloan

Semua warisan produk budaya benda tersebut terkonsentrasi di Loloan Timur. Namun untuk warisan produk budaya tak benda seperti bahasa Melayu Loloan, kesenian Adrah dan beladiri Silat Bugis dijumpai di kedua wilayah. Hasil wawancara dengan masyarakat lokal menjelaskan mengenai perkiraan lokasi keberadaan situs Benteng Fatimah yaitu di Loloan Timur, dengan batas berupa jelinjing yang melintas tidak jauh dari jalan utama di Lingkungan Loloan Timur. 


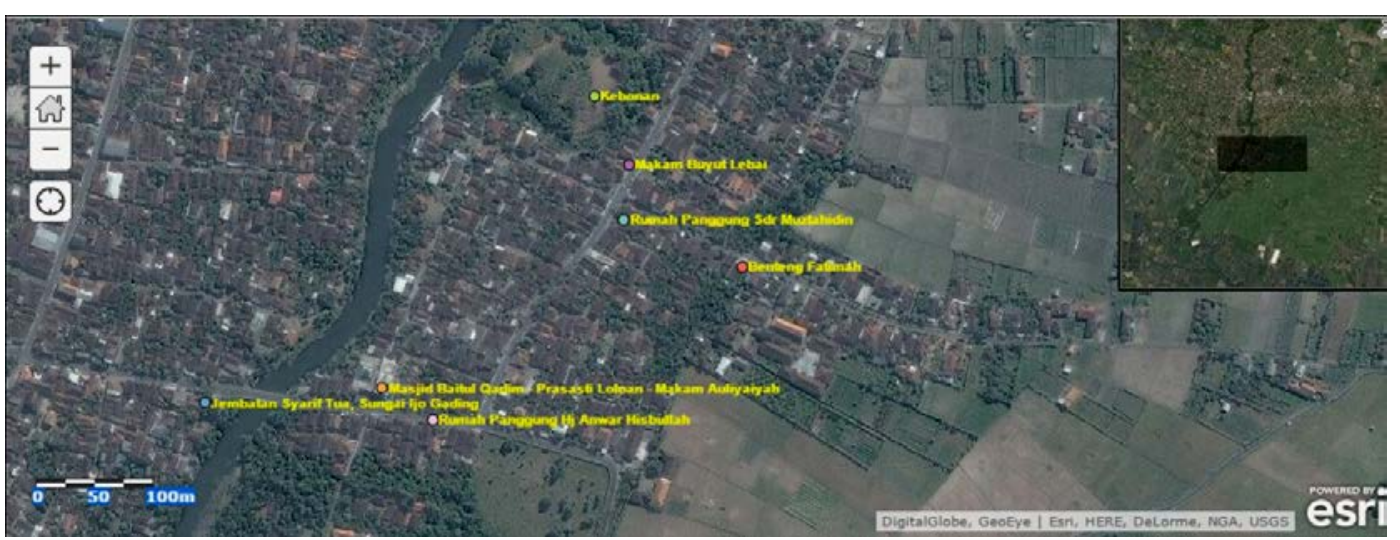

Sumber: Google Earth, pengolahan dengan ArcGIS online

Gambar 9. Distribusi Spasial Kawasan Bernilai Budaya dan Sejarah

\section{Simpulan}

Hasil penelitian ini menunjukkan bahwa pengorganisasian ruang di Kampung Loloan saat ini merujuk pada pembagian ruang masyarakat bahari yang merupakan masyarakat nelayan dimana pembagian zona ruangnya berdasarkan pembagian zona ekologis sungai (perairan) yaitu zona hulu (Lingkungan Ketugtug dan Pertukangan), zona tengah (Lingkungan Loloan Timur dan Kerobokan), serta zona hilir (Lingungan Mertasari dan Terusan). Sedangkan pendistribusian secara spasial dari kawasan bernilai budaya dan sejarah terkonsentrasi di wilayah Loloan Timur yang merupakan tempat tinggal masyarakat pendatang gelombang pertama ke Kerajaan Jembrana dimana kelompok tersebut merupakan masyarakat yang berasal dari etnis Melayu dan Bugis.

\section{Daftar Pustaka}

Bojie, F., Chen, L. 1996. Landscape Diversity Types and and Their Ecological Significance. Acta Geographica Sinica. Vol. 51. Issue. 5. ISSN: 0375-5444

Pramesti, D. S. 2014. Sistem Spasial dan Tipologi Rumah Panggung di Desa Loloan, Jembrana (Bali). E-Jurnal: Ruang-Space (Jurnal Lingkungan Binaan) Vol. 1 No.1 April 2014.

Profil Kelurahan Loloan Barat. 2014. Kelurahan Loloan Barat. Jembrana

Suparwa, I. N. 2008. Ekologi Bahasa dan Pengaruhnya dalam Dinamika Kehidupan Bahasa Melayu Loloan Bali. Jurnal Lingkungan Hidup Bumi Lestari Vol. 8 No. 1. Halaman 74-81

Suryawati, C.I. 2009. Kehidupan Masyarakat Kampung Loloan Pada Masa Kerajaan Jembrana Abad ke-19. Jurnal Penelitian Sejarah dan Nilai Tradisional Volume 31 No. 3. Halaman 38-57

\section{Ucapan Terima kasih}

Ucapan terima kasih penulis sampaikan kepada Universitas Udayana khususnya LPPM yang telah membiayai penelitian ini melalui skim penelitian Hibah Penelitian Dosen Muda (HPDM) Tahun 2015. 